\title{
Inflammatory Bowel Disease in Pediatric Patients
}

Characteristics of Newly Diagnosed Patients From the CEDATA-GPGE Registry

\author{
Stephan Buderus*, Dietmar Scholz*, Rolf Behrens, Martin Classen, Jan De Laffolie, Klaus-Michael \\ Keller, Klaus-Peter Zimmer, Sibylle Koletzko for the CEDATA-GPGE Study Group**
}

\section{SUMMARY}

Background: Inflammatory bowel disease (IBD) can arise at any age, with peak incidence in adolescence and young adulthood. A registry of pediatric cases of IBD offers the opportunity to document their diagnosis and treatment, with the ultimate aim of improving diagnosis and treatment in the future.

Methods: In the German-language CEDATA-GPGE registry, 3991 cases of IBD in patients less than 18 years of age were documented from 2004 to 2014. The 1257 patients who were prospectively included in the registry upon diagnosis and whose further course was documented for at least three months were analyzed in two separate groups-under 10 years old, and 10 years and above-with respect to the type and duration of their symptoms until diagnosis, the completeness of the diagnostic evaluation, the disease phenotype, and the initial treatment.

Results: Of the 958 patients for whom full documentation was available, $616(64.3 \%)$ had Crohn's disease (CD), 278 (29\%) had ulcerative colitis (UC), 64 (6.7\%) had an unclassified IBD, and $23.2 \%$ were under 10 years old. The latency to diagnosis was longer for $\mathrm{CD}$ than for $\mathrm{UC}$ ( 0.5 versus 0.3 years), regardless of age. $62.5 \%$ of the $\mathrm{CD}$ patients had ileocolonic involvement, and more than half had involvement of the upper gastrointestinal tract. $71 \%$ of the patients with UC had subtotal colitis or pancolitis. Continuous improvement was seen in diagnostic assessment according to published guidelines. For example, in 2004/2005, $69 \%$ of patients were evaluated endoscopically with ileocolonoscopy and esophagogastroduodenoscopy; this fraction had risen to nearly $100 \%$ by $2013 / 2014$. Similarly, the percentage of patients who underwent a diagnostic evaluation of the small intestine, as recommended, rose from $41.2 \%$ to $60.9 \%$ over the same period. The most common initial treatments were 5 -aminosalicylates ( $86.8 \% \mathrm{CD}, 100 \% \mathrm{UC})$ and glucocorticoids ( $60.6 \% \mathrm{CD}, 65.6 \% \mathrm{UC}) .32 \%$ of the patients with $\mathrm{CD}$ received exclusive enteral nutrition therapy.

Conclusion: Most of these pediatric patients with IBD, whether in the younger or the older age group, had extensive bowel involvement at the time of diagnosis. The registry data imply that improvement in clinical course may be achieved by shortening the time to diagnosis and by closer adherence to the diagnostic and therapeutic guidelines.

\section{$>$ Cite this as:}

Buderus S, Scholz D, Behrens R, et al. for the CEDATA-GPGE study group: Inflammatory bowel disease in pediatric patients - characteristics of newly diagnosed patients from the CEDATA-GPGE registry. Dtsch Arztebl Int 2015; 112 : 121-7. DOI: 10.3238/arztebl.2015.0121

\footnotetext{
* These two authors share first authorship.

** For a list of members of the CEDATA-GPGE study group please see eSupplement Department of Pediatrics, St. Marien-Hospital, GFO-Kliniken Bonn: Dr. med. Buderus Department of General Pediatrics and Neonatology, Center for Pediatric and Adolescent Care, Justus Liebig University, Gießen, and Department of Child and Adolescent Psychiatry, Psychotherapy and Psychosomatics, University of Leipzig: Dr. med. Scholz AG CEDATA of the GPGE; Erlangen: Prof. Dr. med. Behrens

Department of Pediatric and Adolescent Medicine, Klinikum links der Weser, Bremen: Dr. med. Classen Department of Pediatrics, DKD Helios Klinik Wiesbaden, Prof. Dr. med. Keller

Department of General Pediatrics and Neonatology, Center for Pediatric and Adolescent Care, Justus Liebig University, Gießen: Prof. Dr. med. Zimmer, Dr. med. Laffolie

Department of Pediatric Gastroenterology and Hepatology, Dr von Hauner Children's Hospital, Ludwig

Maximilians University of Munich: Prof. Dr. med. Koletzko
}

5 wenty per cent of cases of inflammatory bowel disease (IBD), the two major forms of which are Crohn's disease and ulcerative colitis, are diagnosed before the patient's twentieth birthday $(1,2)$. As a chronic, relapsing disease, IBD jeopardizes young people's physical, psychosocial, and occupational development. In recent decades there has been a general increase in the incidence and prevalence of IBD in both industrialized and emerging countries (3). A shift toward earlier onset of IBD has been observed within pediatrics (4). Recent studies indicate incidence rates of approximately 5 to 11 per 100000 children and adolescents under the age of 18 years $(2,5)$. With 13.4 million children and adolescents living in Germany (German Federal Statistical Office 2011), this means between 800 and 1470 new pediatric cases per year.

Every doctor who treats children and adolescents should be familiar with the early signs of IBD. The Robert Koch Institute's German Health Interview and Examination Survey for Children and Adolescents (KiGGS, Kinder- und Jugendgesundheitssurvey) shows that only $38 \%$ of $\mathrm{J} 1$ check-up examinations for young people are performed by a pediatrician; the remainder are performed by a family doctor or a doctor with another specialty (6). Identifying patients of all ages as early as possible and referring them for further diagnosis to a pediatric hospital with a pediatric gastroenterology facility or to a pediatric gastroenterologist is an important task for pediatricians, family doctors, and internists.

The most common initial symptoms of IBD are nonspecific: chronic abdominal pain, diarrhea, and failure to gain weight $(1,7,8)$. Abdominal pain in particular is a typical complaint among children and adolescents (9). Analysis of the KiGGS study on the subject of pain showed that $69.3 \%$ of children aged between three and 10 years, and $59.6 \%$ of adolescents aged between 11 and 17 years, had suffered from abdominal pain at least once in the last three months; $14.5 \%$ and $18.0 \%$ respectively suffered from abdominal pain on a weekly basis (10). Because of this high prevalence, abdominal complaints are sometimes classified as "functional" and not subjected to targeted inquiry into any further warning signs that might indicate IBD. Further investigation should be performed in cases of loss of appetite, 


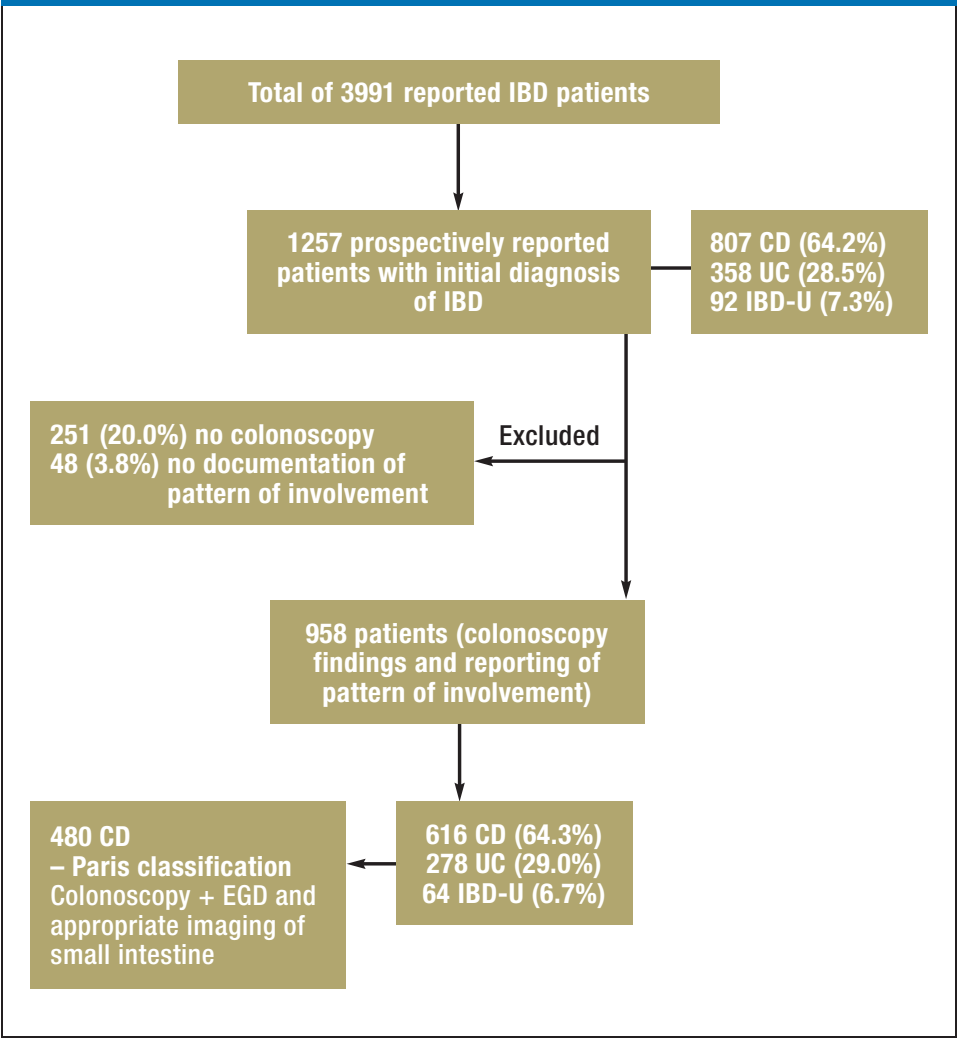

Description of patient cohorts of CEDATA-GPGE registry

$\mathrm{CD}$, Crohn's disease; IBD, inflammatory bowel disease; UC, ulcerative colitis; IBD-U, unclassified inflammatory bowel disease; EGD, esophagogastroduodenoscopy loss of weight, diarrhea, blood in stool, fatigue, joint complaints, anal fissures or skin tags, or family history of IBD. If clinical history and physical examination including anal examination confirm suspicion of IBD, laboratory testing including fecal inflammation markers (calprotectin or lactoferrin) should be performed. Normal fecal markers rule out active IBD to a large extent (11).

The Society for Pediatric Gastroenterology and Nutrition (GPGE, Gesellschaft für Pädiatrische Gastroenterologie und Ernährung) established the CEDATA-GPGE registry in 2004 in order to obtain data on the epidemiology, pattern of involvement, diagnosis, treatment, and quality of care of pediatric patients with IBD in Germany and Austria. Results on latency of diagnosis in 2436 pediatric patients with IBD were published in 2011 (12). When IBD was diagnosed later, growth delay was often already present. Early diagnosis improves patients' care and prognosis. The paper published in 2011 included all patients. Because more than one year had elapsed between inclusion in the registry and diagnosis in $42 \%$ of the children, error in the results for symptoms at manifestation as a result of recall bias cannot be ruled out (12).

This article aims to describe the initial symptoms and disease phenotype in relation to age, and to investi-

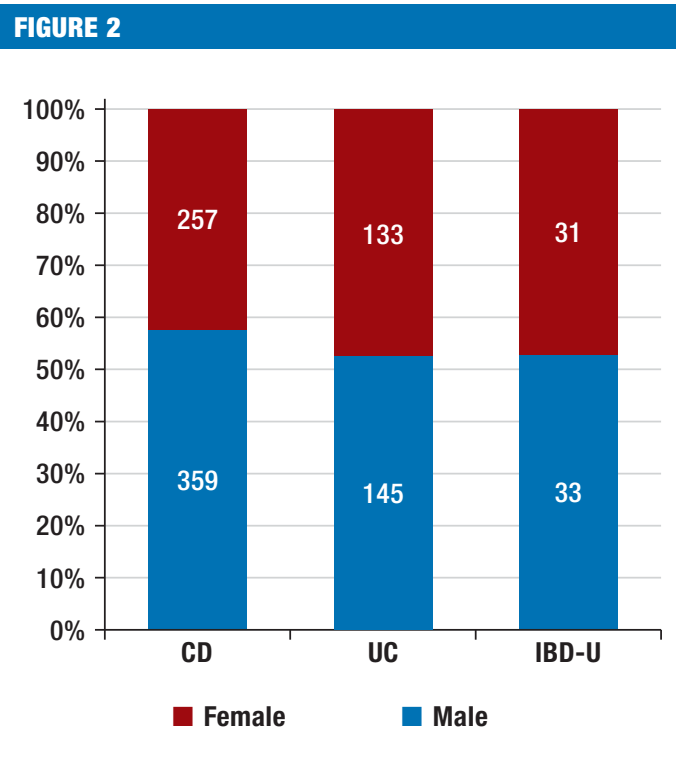

Diagnoses and sex distribution of 958 patients with new-onset inflammatory bowel disease

CD, Crohn's disease; UC, ulcerative colitis;

IBD-U, unclassified inflammatory bowel disease

gate adherence to the pediatric guidelines on IBD diagnosis published by the European Society for Pediatric Gastroenterology, Hepatology and Nutrition (ESPGHAN) published in 2005 (13). The degree of compliance with these guidelines serves as a quality indicator. Only patients who were included in the registry on or shortly after diagnosis were evaluated. The disease phenotype (14), i.e. the location and severity of inflammation and characteristics such as fistulas and stenosis as markers of disease severity, was divided by age; initial therapy was analyzed in terms of guideline recommendations.

\section{Patients, methods}

Children and adolescents aged under 18 years and with a confirmed diagnosis of Crohn's disease, ulcerative colitis, or unclassified IBD (IBD-U) were reported to the CEDATA-GPGE registry with the written consent of patients or their parents/guardians. Reports were voluntarily submitted from 84 hospitals, clinics, and practices in Germany and Austria. In all, 12 hospitals submitted reports on 100 patients to the registry, 26 hospitals submitted reports on between 31 and 100 patients, and 46 hospitals submitted reports on up to 30 patients. Of a total of 3991 patients, 1257 were included in the registry within 90 days of diagnosis and were included in this analysis.

\section{Database structure, reporting forms}

The registry was inititated und funded by the GPGE in July 2014. From 2004 to July 2010, data sheets were submitted by postal mail, and data was inputted centrally. No new patients were included in the registry 


\section{Clinical history and initial symptoms at diagnosis}

\begin{tabular}{|c|c|c|c|c|c|c|}
\hline \multirow[t]{2}{*}{ Symptoms, clinical history } & \multicolumn{2}{|c|}{ Ulcerative colitis ( $n=278$ ) } & \multicolumn{2}{|c|}{ Crohn's disease $(n=616)$} & \multicolumn{2}{|c|}{ IBD-U $(n=64)$} \\
\hline & $\begin{array}{c}<10 \text { years } \\
(n=71)\end{array}$ & $\begin{array}{c}\geq 10 \text { years } \\
(n=207)\end{array}$ & $\begin{array}{c}<10 \text { years } \\
(n=132)\end{array}$ & $\begin{array}{c}\geq 10 \text { years } \\
(n=484)\end{array}$ & $\begin{array}{c}<10 \text { years } \\
(n=19)\end{array}$ & $\begin{array}{c}\geq 10 \text { years } \\
(n=45)\end{array}$ \\
\hline Abdominal pain & $42(59.2 \%)$ & $164(79.2 \%)$ & $102(77.3 \%)$ & $377(77.9 \%)$ & $11(57.9 \%)$ & $33(73.3 \%)$ \\
\hline Diarrhea & $64(90.1 \%)$ & $179(86.5 \%)$ & $87(65.9 \%)$ & $328(67.8 \%)$ & $14(73.7 \%)$ & $35(77.8 \%)$ \\
\hline Blood in stool & $63(88.7 \%)$ & $175(84.5 \%)$ & $62(47.0 \%)$ & $161(33.3 \%)$ & $18(94.7 \%)$ & $32(71.1 \%)$ \\
\hline Failure to gain weight/weight loss & $25(35.2 \%)$ & $83(40.0 \%)$ & $61(46.2 \%)$ & $311(64.3 \%)$ & $8(42.1 \%)$ & $23(51.1 \%)$ \\
\hline Growth disorder & $5(7.0 \%)$ & $4(1.9 \%)$ & $14(10.6 \%)$ & $57(11.8 \%)$ & $1(5.2 \%)$ & $1(2.2 \%)$ \\
\hline Fever & $7(9.9 \%)$ & $16(7.7 \%)$ & $30(22.7 \%)$ & $78(16.1 \%)$ & 0 & $3(6.7 \%)$ \\
\hline Anemia & $22(31.0 \%)$ & $66(31.9 \%)$ & $32(24.2 \%)$ & $134(27.7 \%)$ & $6(31.6 \%)$ & $10(22.2 \%)$ \\
\hline Reduced performance & $13(18.3 \%)$ & $74(35.7 \%)$ & $41(31.1 \%)$ & $216(44.6 \%)$ & $4(21.1 \%)$ & $17(37.8 \%)$ \\
\hline Loss of appetite & $10(14.1 \%)$ & $30(14.5 \%)$ & $34(25.8 \%)$ & $111(22.9 \%)$ & $1(5.2 \%)$ & $6(13.3 \%)$ \\
\hline Extraintestinal manifestations (eyes, skin, liver, joints) & $5(7.0 \%)$ & $41(19.8 \%)$ & $17(12.9 \%)$ & $58(12.0 \%)$ & $2(10.5 \%)$ & $7(15.6 \%)$ \\
\hline Family history of IBD & $13(18.3 \%)$ & $32(15.5 \%)$ & $29(22.0 \%)$ & $75(15.5 \%)$ & $2(10.5 \%)$ & $7(15.6 \%)$ \\
\hline Latency of diagnosis (years; median/interquartile range) & $0.3(0.8)$ & $0.3(0.4)$ & $0.5(0.8)$ & $0.5(0.7)$ & $0.3(0.4)$ & $0.4(0.3)$ \\
\hline
\end{tabular}

IBD, inflammatory bowel disease; IBD-U, unclassified inflammatory bowel disease

between July 2010 and July 2013, for logistical and financial reasons. Since August 2013 reports have been submitted online, via an Internet-based platform.

The database and reporting procedure were examined and approved by the relevant ethics committees and data protection employees of the three institutions that maintained the registry during the time period covered by the research (Institute for Medical Informatics and Biometry [IMB] of Technische Universität Dresden; Institute of Epidemiology at the Helmholtz Zentrum, LMU Munich; Department of General Pediatrics and Neonatology, JLU Giessen). The Austrian hospitals that participated also obtained local ethics approval.

Data was gathered using two reporting forms: one for initial presentation, and the second for all other follow-up examiations. (eFigure 1, eFigure 2). Both of these were slightly modified in 2008. The initial form was completed on inclusion in the registry and covers initial symptoms, including extraintestinal manifestations, time from initial symptoms to diagnosis, and family history of inflammatory bowel disease. The follow-up form was completed whenever possible when the patient presented to a physician, but at least twice per year. It included clinical and paraclinical information, and diagnosis and treatment measures. The pediatric Crohn's disease activity index (PCDAI) (15) and ulcerative colitis activity index (PUCAI) (16) can be calculated to assess disease activity.

\section{Diagnosis and initial treatment}

According to the guidelines, diagnosis of inflammatory bowel diseases in children and adolescents includes ileocolonoscopy and esophagogastroduodenoscopy (EGD) with stepwise biopsy, in addition to clinical history, clinical examination, and laboratory testing (13, 17). Imaging of the small intestine, preferably using MR enteroklysis, is essential for Crohn's disease and IBD-U and optional for ulcerative colitis. This diagnostic procedure, which is more comprehensive than that for adult IBD patients, is recommended because macroscopically visible Crohn's lesions up to and including deep ulcerations in the esophagus, stomach, or duodenum can be detected at diagnosis in approximately $50 \%$ of pediatric Crohn's disease patients, and this has consequences for treatment (18). Comprehensive diagnostics must be performed in order to identify disease phenotype according to the pediatric Paris classification (eFigure 3) (14). This includes age at diagnosis, severity of disease, and complications such as fistulas, stenosis, and growth delay. The percentage of patients diagnosed according to the guidelines was calculated over time, in order to determine any improvement in quality of diagnosis.

Initial therapy was evaluated on the basis of the follow-up reporting forms for the first three months following diagnosis. Patients for whom a minimum of 3 months' documentation of clinical course was not available in the registry were not included in the analysis.

\section{Results}

The 1257 patients with new-onset disease (Figure 1) were reported from 77 hospitals and practices (median per reporter: 5 patients; range: 1 to 110). It proved necessary to exclude 299 patients (23.8\%) from 
TABLE 2a

\section{Pattern of involvement at diagnosis of Crohn's disease}

\begin{tabular}{ll|c|c|c|c}
\multicolumn{2}{l|}{$\begin{array}{c}\mathrm{L} 1 \\
(n=64)\end{array}$} & $\begin{array}{c}\mathrm{L} 2 \\
(n=95)\end{array}$ & $\begin{array}{c}\mathrm{L} 3 \\
(n=300)\end{array}$ & $\begin{array}{c}\mathrm{L} 4 \mathrm{a} \\
(n=225)\end{array}$ & $\begin{array}{c}\mathrm{L} 4 \mathrm{~b} \\
(n=32)\end{array}$ \\
\hline Total & $13.3 \%$ & $19.8 \%$ & $62.5 \%$ & $46.9 \%$ & $6.7 \%$ \\
\hline$<10$ years & $11.8 \%$ & $18.3 \%$ & $66.7 \%$ & $47.3 \%$ & $4.3 \%$ \\
\hline$\geq 10$ years & $13.7 \%$ & $20.2 \%$ & $61.5 \%$ & $46.8 \%$ & $7.2 \%$
\end{tabular}

Age group $<10$ years $(n=93,19.4 \%)$; age group $\geq 10$ years $(n=387,80.6 \%)$

Paris classification for Crohn's disease: L1: distal 1/3 ileum \pm cecal involvement; L2: colonic; L3: ileocolon L4a: upper disease proximal to ligament of Treitz; L4b: upper disease distal to ligament of Treitz and proximal to distal $1 / 3$ ileum

\section{TABLE 2b}

Pattern of involvement at diagnosis of ulcerative colitis

\begin{tabular}{ll|c|c|c}
$\begin{array}{l}\text { E1 } \\
(n=15)\end{array}$ & $\begin{array}{c}\text { E2 } \\
(n=52)\end{array}$ & $\begin{array}{c}\text { E3 } \\
(n=23)\end{array}$ & $\begin{array}{c}\text { E4 } \\
(n=178)\end{array}$ \\
\hline Total & $5.3 \%$ & $18.5 \%$ & $8.2 \%$ & $63.4 \%$ \\
\hline$<10$ years & $1.4 \%$ & $17.8 \%$ & $9.6 \%$ & $67.1 \%$ \\
\hline$\geq 10$ years & $6.7 \%$ & $18.7 \%$ & $7.7 \%$ & $62.0 \%$
\end{tabular}

Age group $<10$ years $(n=73,26 \%)$; age group $\geq 10$ years $(n=208,74 \%)$

E1: proctitis; E2: left-side colitis; E3: extensive (proximal to splenic flexure); E4: pancolitis (proximal to hepatic flexure)

\section{TABLE 3}

Treatment in the first three months following diagnosis

\begin{tabular}{l|c|c|c}
\hline Drug & $\begin{array}{c}\mathrm{CD} \\
(n=658)\end{array}$ & $\begin{array}{c}\text { UC } \\
(n=228)\end{array}$ & $\begin{array}{c}\text { IBD-U } \\
(n=67)\end{array}$ \\
\hline (Methyl) prednisolone & $60.6 \%$ & $65.6 \%$ & $55.1 \%$ \\
\hline Budesonide (oral) & $20.7 \%$ & $1.7 \%$ & $4.5 \%$ \\
\hline Mesalazine or sulfasalazine & $86.8 \%$ & $100 \%$ & $100 \%$ \\
\hline Exclusive enteral nutrition & $32.0 \%$ & $6.2 \%$ & $10.1 \%$ \\
\hline Infliximab & $1.7 \%$ & $0.7 \%$ & $3 \%$ \\
\hline Methotrexate & $0.5 \%$ & $0.3 \%$ & $0 \%$ \\
\hline Thiopurine & $45.4 \%$ & $27.4 \%$ & $20.9 \%$ \\
\hline Probiotics & $5.5 \%$ & $20.8 \%$ & $13.4 \%$ \\
\hline Antibiotics & $18.1 \%$ & $9.7 \%$ & $19.4 \%$ \\
\hline
\end{tabular}

CD, Crohn's disease; UC, ulcerative colitis; IBD-U, unclassified inflammatory bowel disease phenotype classification because endoscopic examinations or pattern of involvement had not been recorded. The remaining population consisted of 958 patients, of whom 616 had Crohn's disease $(64.3 \%$; age: 0.3 to 17.9 years; median: 13.0), 278 ulcerative colitis (29.0\%; age: 0.8 to 17.7 ; median: 12.6 ), and 64 IBD-U (6.7\%; age: 0.4 to 17.6 ; median: 11.9 ). More boys than girls suffered from Crohn's disease (Figure 2). Age at diagnosis was less than six years in $7.6 \%$ of the children and under 10 years in $23.2 \%$ (corresponding to Ala of the Paris classification) (14) (eFigure 4).

Table 1 shows clinical symptoms and extraintestinal manifestations before or at diagnosis of IBD, positive family history of inflammatory bowel disease, and latency of diagnosis, by diagnosis and for ages $<10$ years and $\geq 10$ years. There are larger differences in "blood in stool," which is reported substantially more frequently in ulcerative colitis and IBD-U. Children under 10 years were more likely to have a positive family history of inflammatory bowel disease.

\section{Disease phenotype according to the Paris classification}

Only patients for whom ileocolonoscopy, esophagogastroduodenoscopy, and imaging of the small intestine were recorded $(n=480)$ were evaluated for phenotyping of Crohn's disease (14). The ileum and colon were affected (L3) in almost two-thirds of patients with Crohn's disease, while ileocecal involvement alone was present in only $13.3 \%$ of cases (Table 2, eFigure 2). Approximately half had Crohn's lesions in the upper gastrointestinal tract, and $7.2 \%$ also in the small intestine $(\mathrm{L} 4 \mathrm{a}+\mathrm{b})$. Penetrating disease with fistula formation (B3) or stenosis (B2) was found in 2.1\% and $2.8 \%$ of patients respectively; the remaining $95.1 \%$ had purely luminal involvement. Perianal changes with deep fissures, fistulas, or abscesses were recorded in $11.5 \%$ of cases (feature "p"). Extensive or pancolitis (E3 or E4) was present at diagnosis in $75 \%$ of patients with ulcerative colitis.

\section{Compliance with guidelines for diagnosis of inflammatory bowel disease}

Ileocolonoscopy was recorded for 703 patients, colonoscopy without intubation of the terminal ileum in 239, and rectosigmoidoscopy in 16. Esophagogastroduodenoscopy was performed on 753 patients. Imaging of the small intestine involved using magnetic resonance imaging in 335 cases, X-ray examination in 115 cases, and computed tomography combined with ultrasound in six cases. Comparative evaluation by registry year shows that the percentage of patients undergoing the recommended examinations rose steadily between 2004/2005 and 2014 (Figure 3). This increase occurred in all three forms of inflammatory bowel disease. Since 2004 there has been an increase in MRI examinations for diagnostics of the small intestine, from $19.4 \%$ (95\% confidence interval [CI]: $13.7 \%$ to $26.3 \%$ ) to $56.5 \%$ (95\% CI: $34.5 \%$ to $76.8 \%$ ), whereas there was a sharp decrease in X-ray examinations. 


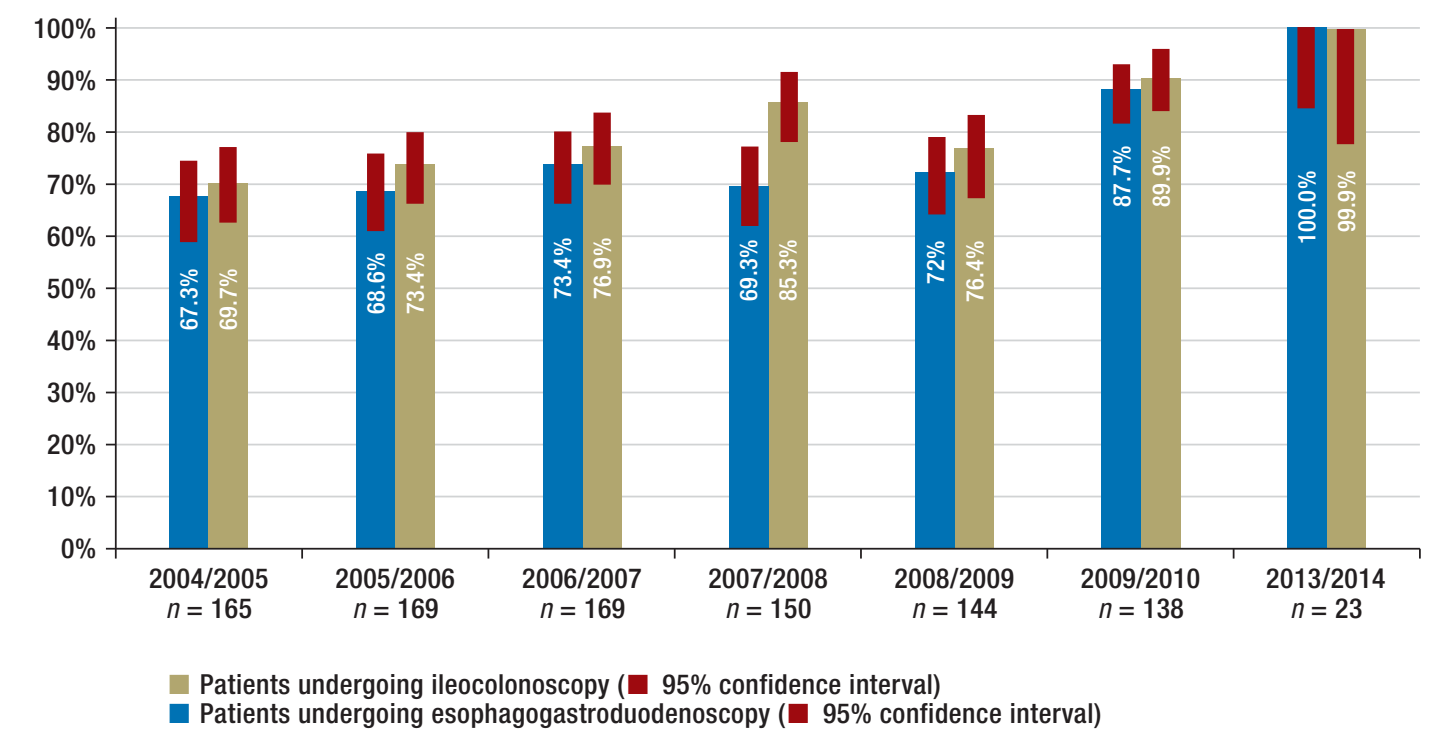

Overall, the percentage of patients receiving imaging of the small intestine according to the guidelines increased during the observation period from $41.2 \%(95 \% \mathrm{CI}$ : $33.6 \%$ to $49.1 \%$ ) to $60.9 \%$ (95\% CI: $38.5 \%$ to $80.3 \%$ ) (eFigure 5).

\section{Initial pharmacological therapy}

Evaluation of initial pharmacological therapy included the reporting forms for the first three months (Table 3). One form each was available for evaluation for 524 children, two forms each for 342 children, three for 196 , four for 77, and between five and nine for 46 .

Table 3 shows the forms of therapy for 1013 patients with reporting forms for the first three months, by diagnosis. Exclusive enteral nutrition to induce remission, i.e. exclusive liquid or tube feeding, was administered to $32.2 \%$ of Crohn's disease patients (19). This form of therapy was not systematically recorded until 2008, so this percentage is in relation to patients who developed the disease after that date.

Maintenance therapy involving thiopurines (azathioprine or mercaptopurine) was begun in $21 \%$ of patients with IBD-U, $27 \%$ of those with ulcerative colitis, and $45 \%$ of those with Crohn's disease. Only a small number of patients received infliximab in the first three months.

\section{Discussion}

Analysis of the pediatric IBD patients documented in the CEDATA-GPGE registry shows the particular features of this disease when it begins in childhood or adolescence. Almost one in four patients was below the age of 10 years at diagnosis. Crohn's disease occurred almost twice as frequently as ulcerative colitis. The fact that Crohn's disease accounts for most cases of inflammatory bowel disease in pediatric patients is in line with data from the European pediatric registry EUROKIDS (18). In adulthood the proportions of the two diseases are more equal $(20,21)$. The registry data shows that extensive inflammatory involvement is present in affected children and adolescents already at disease onset. The small and large intestines were affected in $62.5 \%$ of cases of Crohn's disease, and the esophagus, stomach, or upper small intestine in 59\% of cases. Isolated ileocecal involvement, which is typical in adulthood (21), was rare in children and adolescents, occurring in only $13.3 \%$ of cases. In the present study and the EUROKIDS cohort (18) extensive colitis is recorded when ulcerative colitis is diagnosed in $75 \%$ of children and adolescents; this is the case for only $27 \%$ to $47.6 \%$ of adults $(20-22)$. Left-side colitis or proctitis was diagnosed in $6.7 \%$ of those aged 10 years and older and only $1.4 \%$ of younger patients; in contrast, such limited inflammation is present in approximately one-third of adults with ulcerative colitis.

Surprisingly, there was little difference in the frequency of symptoms that led to a diagnosis of inflammatory bowel disease between either diagnosis groups or age groups. There were major differences in the occurrence of blood in stool, which was reported in approximately nine in 10 children under the age of 10 years diagnosed with ulcerative colitis or IBD-U but only approximately half of Crohn's disease patients of the same age. This alarm symptom is one of the reasons for the shorter diagnostic delay in ulcerative colitis as compared to Crohn's disease. Colitis or Crohn's-like disease beginning in infancy or early childhood can be a manifestation of primary immunodeficiency with gastrointestinal involvement (23). The registry data does not indicate how frequently such an underlying disease was diagnosed. 
One encouraging sign is the improvement in adherence to the diagnostic guidelines since the registry was established. A matrix was provided to participants to guide data input. Participants received feedback in terms of the completeness of their data, including in comparison with other reporters. Sigmoidoscopy, which was considered insufficient for primary diagnosis, was not recorded after 2007 , for instance. Other pediatric registries also showed an improvement in diagnosis $(24,25)$. The significance of a complete endoscopic work-up has been well demonstrated in the meantime: intubation of the terminal ileum increases the diagnostic yield by $13 \%$, and esophagogastroduodenoscopy confirms diagnosis in $7.5 \%$ of patients with Crohn's disease (25).

Data on initial pharmacological therapy demonstrates the severity of the disease. For example, the majority of patients with Crohn's disease and ulcerative colitis were treated with systemic corticosteroids (prednisolone). While corticosteroids are essential in cases of moderate or severe ulcerative colitis (eBox 1) (26), the pediatric guidelines for the treatment of Crohn's disease published in 2014 state a clear preference for exclusive enteral nutrition to induce remission (eBox 2) (27). The risk/ benefit profile of this is much more favorable than that of steroids (28). During exclusive enteral nutrition patients meet their energy intake needs by formula administration alone for a period of six to eight weeks. The formula is usually drunk but can also be fed through a tube. The biggest obstacle to acceptance of this treatment is not being able to eat normally. Patients must be encouraged to comply with treatment and must be monitored closely while receiving exclusive enteral nutrition. In the CEDATA-GPGE registry exclusive enteral nutrition was not systematically documented until 2008. After that date it was used in almost one-third of patients with Crohn's disease. Mesalazine or sulfasalazine are often prescribed for Crohn's disease. Their use is controversial according to the new guidelines and is only recommended for mild cases (27).

Data evaluation shows both the strengths and the limitations of the registry. CEDATA-GPGE is one of the largest pediatric registries on inflammatory bowel disease internationally, and patients are reported by 84 pediatric hospitals; not all pediatric hospitals are involved, however. The registry does not have records for children and adolescents who are diagnosed and treated by adult gastroenterologists. This explains the apparent decrease in frequency after the age of 14 years. There is therefore a selection bias in favor of younger patients. A further weakness of the registry is incompletely filled out forms, which led to the exclusion of 251 patients from phenotyping. The new online form with mandatory fields reduces the risk of incomplete documentation. The three-year gap in reporting of newly diagnosed patients is also a weakness. Another limitation is the variable frequency with which forms are completed. These methodological problems are caused in part by the voluntary nature of reporting and by underfunding for registry maintenance and evaluation.
In summary, our data shows that children and adolescents of all age groups with inflammatory bowel disease in Germany and Austria are still diagnosed too late. The overwhelming majority already shows signs of extensive involvement at initial manifestation. Although the registry itself has some limitations, the registry data does show significant deviations from the recommended guidelines for diagnosis and initial treatment. Improvements in implementation of diagnostic guidelines over time demonstrate decisively that the registry has the potential to contribute to quality of care.

\section{Acknowledgement}

We would like to thank the other members of the CEDATA-GPGE study group for their intensive collaboration on the work on and with the registry: Renate Abt (Nuremberg), Antje Ballauff (Krefeld), Almuthe Hauer (Graz, Austria), Martin Laass (Dresden), Thomas Lang (Regensburg), and Burkhard Rodeck (Osnabrück).

We would also like to express our gratitude to C. Wendt (Giessen), T. Weidenhausen (Giessen), and A. Brückner (Munich) for their intensive, committed cooperation in database evaluation, without which this paper would not have been possible.

We would like to thank all those involved with the CEDATA-GPGE registry, whose reporting work made this article possible.

The CEDATA-GPGE registry was funded by the Ein Herz für Kinder (A Heart for Children) Foundation and the Falk Foundation.

\section{Conflict of interest statement}

Dr. Buderus has received consultancy fees from MSD. He has received fees for preparing scientific continuing professional development events from AbbVie, MSD, and Nestlé. He has received reimbursement of conference fees from the Falk Foundation.

Dr. Scholz has received fees for preparing scientific continuing professional development events from MSD and Sharp \& Dohme GmbH.

Prof. Keller has received fees for preparing scientific continuing professional development events from Abbott, MSD, SHS, and the Falk Foundation.

Prof. Koletzko has received consultancy fees from MSD, AbbVie, Nestlé Nutrition, Merck, Vifor, and Jannssen. She has received lecture fees from MSD, Nestlé, Danone, Merck, and AbbVie. She has received reimbursement of travel and accommodation expenses and conference fees from MSD and Nestlé. She has received clinical trial funding (third-party funds) from MSD and Janssen. She has received funding for research she herself initiated from Nestlé.

Dr. Classen has received consultancy fees from MSD. He has received fees for preparing scientific continuing professional development events from AbbVie, MSD, and the Falk Foundation. He has received reimbursement of conference fees and travel expenses from MSD and AbbVie.

Prof. Behrens, Prof. Zimmer, and Dr. Laffolie declare that no conflict of interest exists.

\section{KEY MESSAGES}

- Time from symptom onset to diagnosis for inflammatory bowel disease (IBD) among children and adolescents is too long: an average of four to six months.

- The majority of pediatric IBD patients already have extensive involvement at diagnosis.

- Bloody diarrhea is the most important and typical presenting symptom of ulcerative colitis. Other clinical symptoms of Crohn's disease and ulcerative colitis are very similar and independent of age.

- A complete diagnostic work-up is an essential requirement for documentation of disease location and severity. Completeness has improved significantly.

- Initial treatment must follow valid guidelines even more closely. 
Manuscript received on 3 November 2013, revised version accepted on 25 November 2014

Translated from the original German by Caroline Devitt, M.A.

\section{REFERENCES}

1. Kelsen J, Baldassano RN: Inflammatory bowel disease: the difference between children and adults. Inflamm Bowel Dis 2008; 14: 9-11.

2. Benchimol El, Fortinsky KJ, Gozdyra P, van den HM, van LJ, Griffiths AM: Epidemiology of pediatric inflammatory bowel disease: a systematic review of international trends. Inflamm Bowel Dis 2011; 17 423-39.

3. Molodecky NA, Soon IS, Rabi DM, et al.: Increasing incidence and prevalence of the inflammatory bowel diseases with time, based on systematic review. Gastroenterology 2012; 142: 46-54

4. Benchimol El, Guttmann A, Griffiths AM, et al.: Increasing incidence of paediatric inflammatory bowel disease in Ontario, Canada: evidence from health administrative data. Gut 2009: 58: 1490-7.

5. Auvin S, Molinie F, Gower-Rousseau C, et al.: Incidence, clinical presentation and location at diagnosis of pediatric inflammatory bowel disease: a prospective population-based study in northern France (1988-1999). J Pediatr Gastroenterol Nutr 2005; 41: 49-55.

6. Hagen B, Strauch S: The J1 adolescent health check-up: analysis of data from the German KiGGS survey. Dtsch Arztebl Int 2011; 108: 180-6.

7. Sawczenko A, Sandhu BK: Presenting features of inflammatory bowel disease in Great Britain and Ireland. Arch Dis Child 2003; 88: 995-1000.

8. Kugathasan S, Judd RH, Hoffmann RG, et al.: Epidemiologic and clinical characteristics of children with newly diagnosed inflammatory bowel disease in Wisconsin: a statewide population-based study. J Pediatr 2003; 143: 525-31.

9. Bufler P, Gross M, Uhlig HH: Recurrent abdominal pain in childhood Dtsch Arztebl Int 2011; 108: 295-304.

10. Schwille IJ, Giel KE, Ellert U, Zipfel S, Enck P: A community-based survey of abdominal pain prevalence, characteristics, and health care use among children. Clin Gastroenterol Hepatol 2009; 7: 1062-8.

11. Henderson P, Anderson NH, Wilson DC.: The diagnostic accuracy of fecal calprotectin during the investigation of suspected pediatric in flammatory bowel disease: a systematic review and meta-analysis. Am J Gastroenterol 2014; 109: 637-45.

12. Timmer A, Behrens R, Buderus S, et al.: Childhood onset inflammatory bowel disease: Predictors of delayed diagnosis from the CEDATA german-language pediatric inflammatory bowel disease Registry. J Pediatr 2011; 158: 467-73.

13. IBD working group of the European Society for Paediatric Gastroenterology, Hepatology and Nutrition: Inflammatory bowel disease in children and adolescents: recommendations for diagnosis-the Porto criteria. J Pediatr Gastroenterol Nutr 2005; 41: 1-7.

14. Levine A, Griffiths A, Markowitz J, et al.: Pediatric modification of the Montreal classification for inflammatory bowel disease: the Paris classification. Inflamm Bowel Dis 2011; 17: 1314-21.

15. Hyams JS, Ferry GD, Mandel FS, et al.: Development and validation of a pediatric Crohn's disease activity index. J Pediatr Gastroentero Nutr 1991; 12: 439-47.
16. Turner D, Otley AR, Mack, et al.: Development, validation, and evaluation of a pediatric ulcerative colitis activity index: a prospective multicenter study. Gastroenterology 2007; 133: 423-32.

17. Levine A, Koletzko S, Turner D, et al.: ESPGHAN revised porto criteria for the diagnosis of inflammatory bowel disease in children and adolescents. J Pediatr Gastroenterol Nutr 2014; 58: 795-806.

18. de Bie Cl, Paerregaard A, Kolacek S, et al.: Disease phenotype at diagnosis in pediatric Crohn's disease: 5-year analyses of the EUROKIDS Registry. Inflamm Bowel Dis 2013; 19: 378-85.

19. Frivolt K, Schwerd T, Werkstetter KJ, et al.: Repeated exclusive enteral nutrition in the treatment of paediatric Crohn's disease: predictors of efficacy and outcome. Aliment Pharmacol Ther 2014; 39: 1398-407.

20. Van LJ, Russell RK, Drummond HE, et al.: Definition of phenotypic characteristics of childhood-onset inflammatory bowel disease. Gastroenterology 2008; 135: 1114-22.

21. Jakobsen C, Bartek J Jr., Wewer V, et al.: Differences in phenotype and disease course in adult and paediatric inflammatory bowel disease--a population-based study. Aliment Pharmacol Ther 2011; 34: 1217-24.

22. Jess T, Riis L, Vind I, et al.: Changes in clinical characteristics, course, and prognosis of inflammatory bowel disease during the last 5 decades: a population-based study from Copenhagen, Denmark. Inflamm Bowel Dis 2007; 13: 481-9.

23. Uhlig HH, Schwerd T, Koletzko S, et al.: The diagnostic approach to monogenic very early onset inflammatory bowel disease. Gastroenterology 2014; 147: 990-1007.

24. Colletti RB, Baldassano RN, Milov DE, et al.: Variation in care in pediatric Crohn disease. J Pediatr Gastroenterol Nutr 2009; 49: 297-303.

25. de Bie Cl, Buderus S, Sandhu, et al. : Diagnostic workup of paediatric patients with inflammatory bowel disease in Europe: results of a 5-year audit of the EUROKIDS registry. J Pediatr Gastroenterol Nutr 2012; 54: 374-80.

26. Turner D, Levine A, Escher JC, et al.: Management of pediatric ulcerative colitis: joint ECCO and ESPGHAN evidence-based consensus guidelines. J Pediatr Gastroenterol Nutr 2012; 55: 340-61.

27. Ruemmele FM, Veres G, Kolho KL, et al.: Consensus guidelines of ECCO/ESPGHAN on the medical management of pediatric Crohn's disease. J Crohns Colitis 2014; 8: 1179-207.

28. Levine A, Turner D, Pfeffer GT, et al.: Comparison of outcomes parameters for induction of remission in new onset pediatric Crohn's disease: evaluation of the porto IBD group „growth relapse and outcomes with therapy" (GROWTH CD) study. Inflamm Bowel Dis 2014; 20: 278-85

\section{Corresponding author:}

Dr. med. Stephan Buderus

GF0 Kliniken Bonn, Betriebsstätte St. Marien

Robert-Koch-Str. 1

53115 Bonn Venusberg, Germany

paediatrie@marien-hospital-bonn.de

eFigures and eBoxes:

www.aerzteblatt-international.de/15m012 


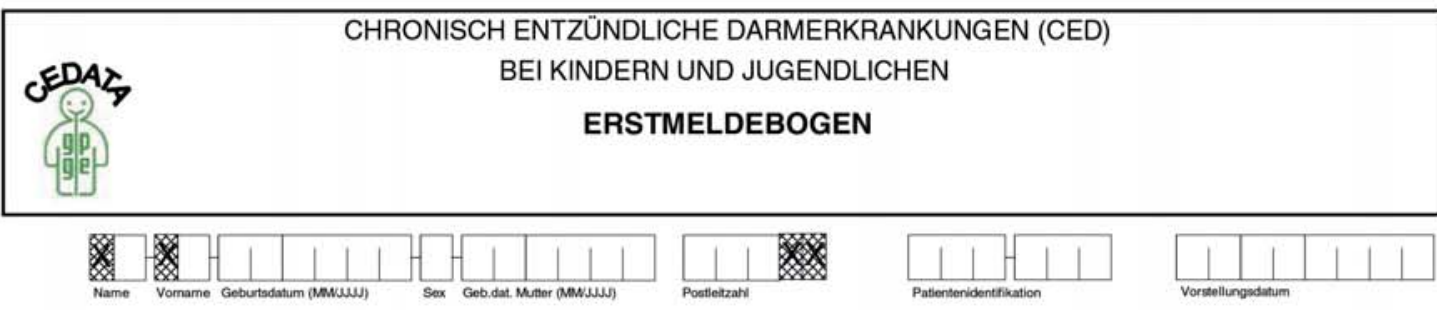

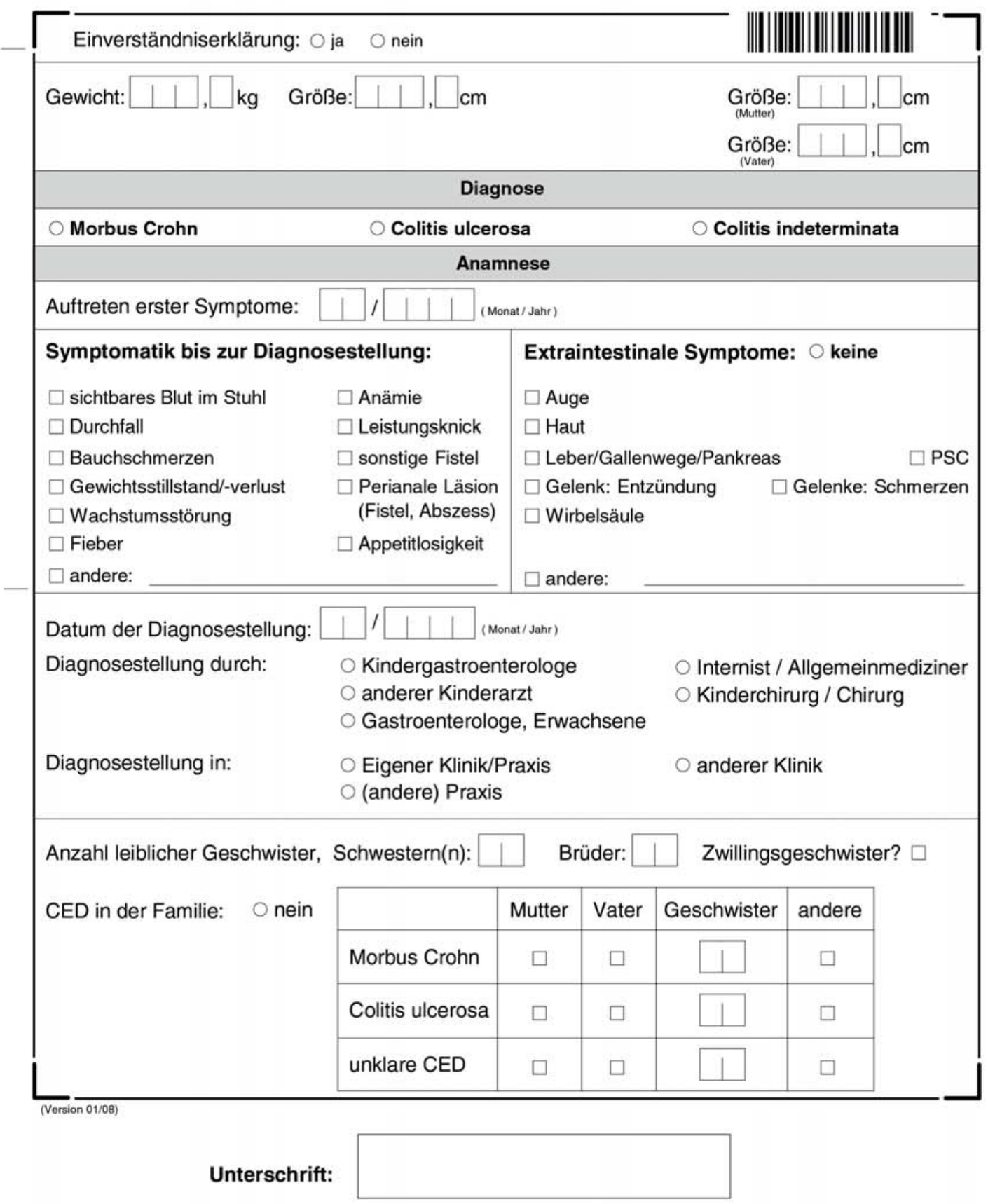




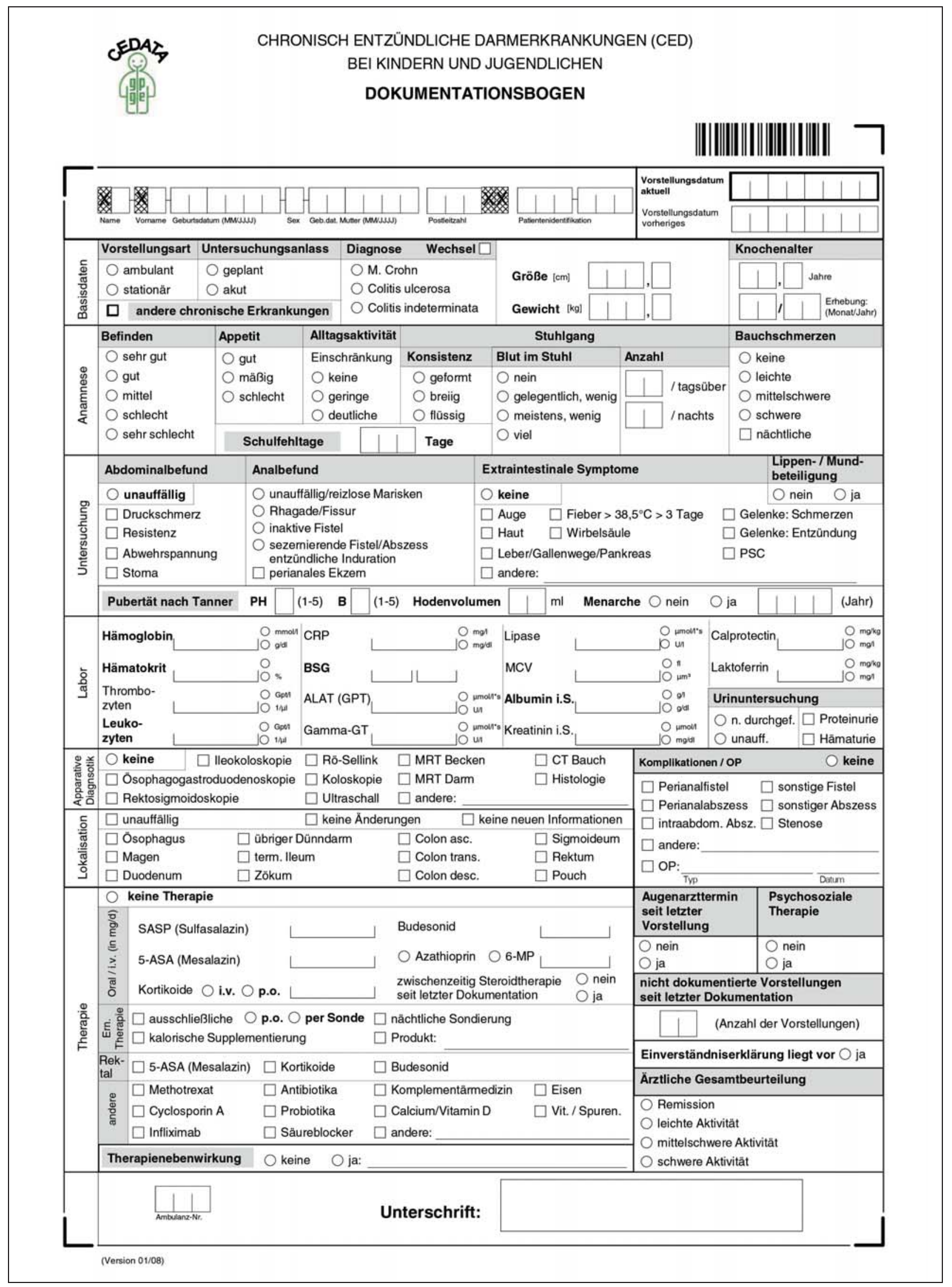




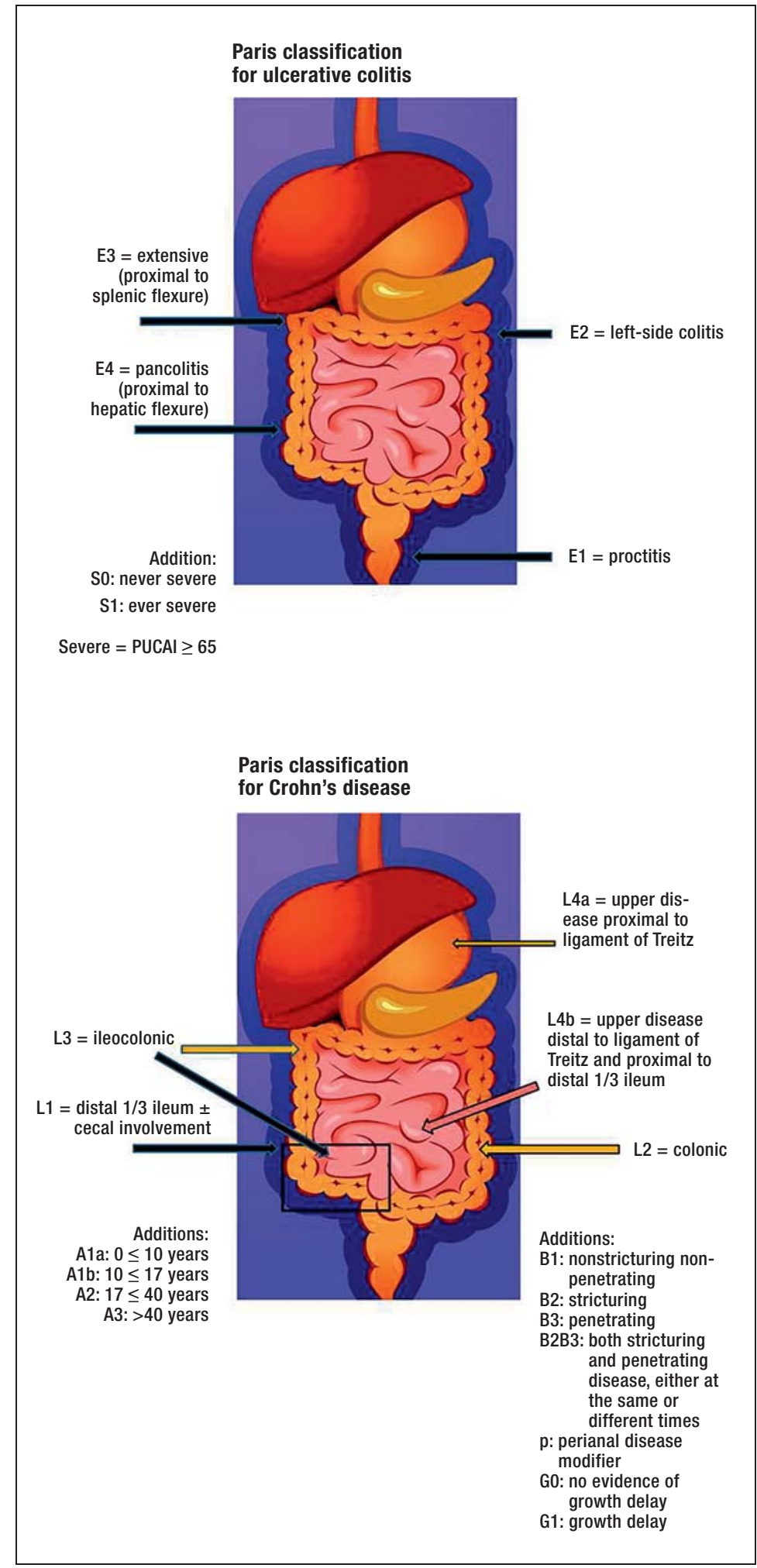

eFigure 3: Graphic representation of Paris classification of disease phenotype, ordered by location of affected portion of intestine

\section{eBOX 1}

\section{Key messages for the treatment of ulcerative colitis (ECCO-ESPGHAN guideline 2012 [26])}

Induction of remission

- Mesalazine for mild to moderate disease activity, combined oral and rectal application recommended

- Prednisolone orally for moderate disease activity, IV administration for high activity

Maintenance therapy

- Mesalazine orally

- Thiopurines (azathioprine): Following acute severe colitis (treated with steroids) or for frequent relapses ( 2 to 3 per year), steroid dependency, or mesalazine intolerance

- Antibiotics: not recommended for regular use

- Probiotics (E. Coli Nissle, VSL\#3): not generally recommended; individual cases such as mesalazine intolerance

\section{Key messages for the treatment of Crohn's disease (ECCO-ESPGHAN guideline 2014 [27])}

Induction of remission

- Exclusive enteral nutrition (EEN)

For 6 to 8 weeks:

First-line therapy in cases of luminal disease, independent of severity

- Budesonide orally for mild to moderate ileocecal involvement

- Prednisolone orally for moderate to severe disease activity, IV administration if no response to oral administration

- Mesalazine orally for mild disease activity

- Antibiotics: for penetrating or perianal disease, for mild to moderate luminal disease

- Anti-TNF- $\alpha$ therapy: for refractory cases or intolerance of steroids and EEN or for penetrating disease

\section{Maintenance therapy}

- Recommended for all patients except mild cases: azathioprine, methotrexate (MTX), anti-TNF-a therapy, possibly partial enteral nutrition in addition

- Option for mild progression only and on complete remission: mesalazine or partial enteral nutrition 


\section{GFIGURE 4}

\section{n patients}

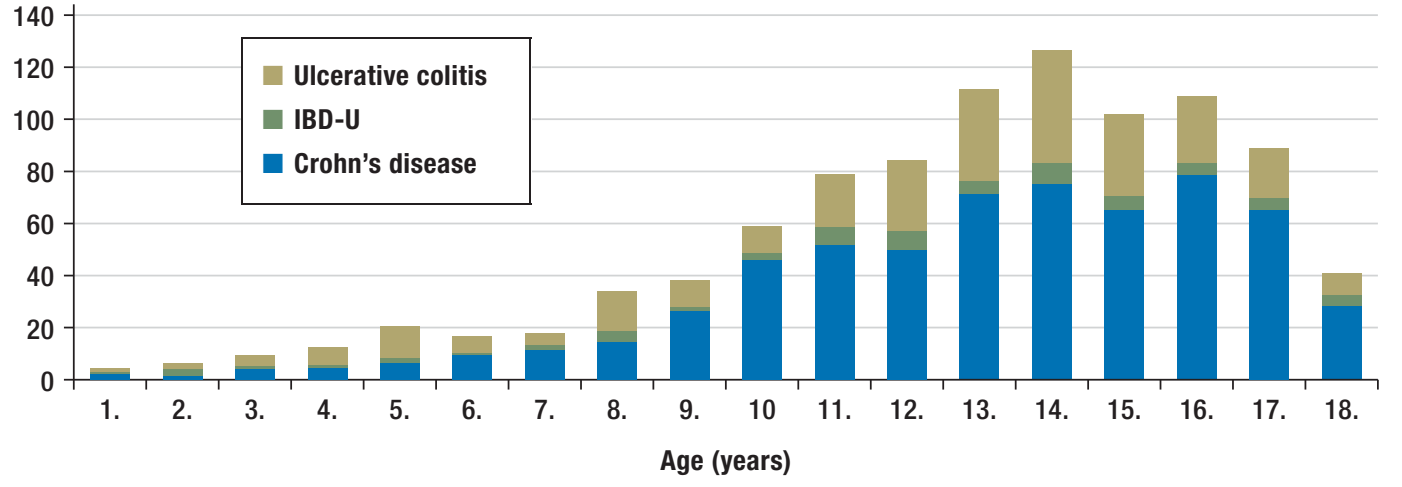

\section{eFIGURE 5}

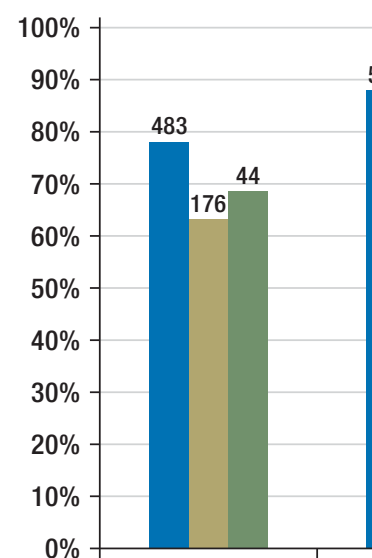

Ileocolonoscopy

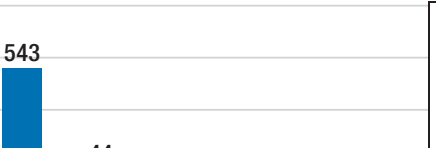

Crohn's disease, $n=616$

Ulcerative colitis, $n=\mathbf{2 7 8}$

Unclassified IBD, $n=64$

166

368

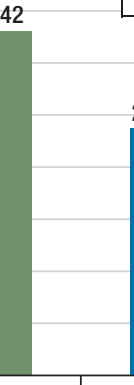

EGD
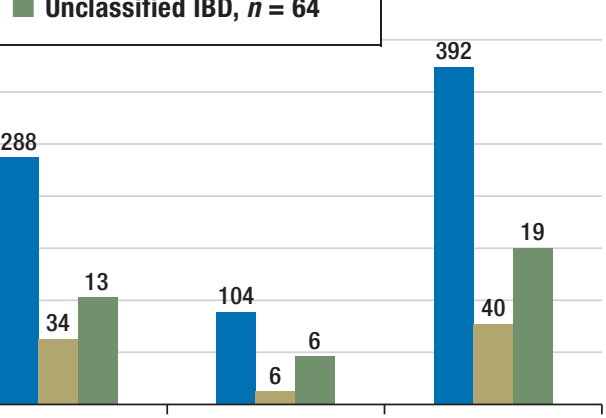

Sellink MRI
Distribution of age at diagnosis of new inflammatory bowel disease (IBD) pa-

tients, by diagnosis. IBD-U, unclassified IBD
Summary of cumulative performance of methods compliant with diagnostic guidelines (reference to all 958 patients) IBD, inflammatory bowel disease; EGD, esophagogastroduodenoscopy; MRI, magnetic resonance imaging 


\section{The CEDATA-GPGE study group}

The following members of CEDATA participated in patient recruitment for this analysis, in addition to those listed as authors:

Rüdiger Adam (Mannheim, Germany), Antje Ballauff (Krefeld, Germany), Barbara Baumgartner (Zwettl, Austria), Thomas Berger (Datteln, Germany), Jens Berrang (Dortmund, Germany), Edith Bieck (Torgau, Germany), Guido Bürk (Herne, Germany), Andreas Busch (Tübingen, Germany), Martin Claßen (Bremen, Germany), Söhnke Dammann (Ravensburg, Germany), Christian Dörfler (Erfurt, Germany), Gesche Düker (Bonn, Germany), Fokko Elschner (Augsburg, Germany), Axel Enninger (Stuttgart, Germany), Annette Findeisen (Greifswald, Germany), Gunter Flemming (Leipzig, Germany), Dirk Föll (Münster, Germany), Marcus Franzke (Salzgitter, Germany), Michael Friedt (Düsseldorf, Germany), Ulrich Gabel (Oberursel, Germany), Rainer Ganschow (Hamburg, Germany), Stephan Gaupp (Nürnberg, Germany), Lars Geerdts (Cottbus, Germany), Johann Gerein (Frankfurt, Germany), Patrick Gerner (Essen, Germany), Alexandra Glettler (Steyr, Austria), Katrin Gröger (Wurzen, Germany), Wiebke Hachmann (Mönchengladbach, Germany), Ralf Hanusch (Rodewisch, Germany), Almuthe Hauer (Graz, Austria), Matthias Heiduk (Plauen, Germany), Peter Heinz-Erian (Innsbruck Austria), Georg Heubner (Dresden, Germany), Monika Hofmann (Chemnitz, Germany), Axel Hübeler (Aue, Germany), Hassan Issa (Leisnig, Germany), Simone Jedwilayties (Friedrichshafen, Germany), Petra Jesche (Hoyerswerda, Germany), Wolfgang Kamin (Hamm, Germany), Hea-Sook Kim-Berger (Marburg, Germany), Peter Klipstein (Quedlinburg, Germany), Ute Kloß (Berlin, Germany), Henrik Köhler (Erlangen, Germany), Andreas Krahl (Darmstadt, Germany), Benno Kretzschmar (Eisenach, Germany), Monika Kurzai (Jena, Germany), Martin Laaß (Dresden, Germany), Thomas Lang (Starnberg, Germany), Ralph Melchior (Kassel, Germany), Michael Melter (Regensburg, Germany), Andreas Möckel (Borna, Germany), Dietrich Ney (Hamburg, Germany), Ralf Pallacks (Memmingen, Germany), Kai Nils Pargac (Riesa, Germany), Maike Petersen (Heidelberg, Germany), Edmund Petri (Münster, Germany), Carsten Posovszky (Ulm, Germany), Markus Prenninger (Wels, Austria), Michael Radke (Potsdam, Germany), Olaf Raecke (Esslingen, Germany), Stefan Rauschenfels (Braunschweig, Germany), Heike Reck (Zittau, Germany), Thomas Richter (Leipzig, Germany), Burkhard Rodeck (Osnabrück, Germany), Frank Schmidt (Halle, Germany), Anjona SchmidtChoudhury (Bochum, Germany), Heike Schoen (Breitenbrunn OT Erlabrunn, Germany), Thomas Scholbach (Chemnitz, Germany), Christina Schwerk (Leipzig, Germany), Wolfgang Sperl (Salzburg, Austria), Armin Stach (Leverkusen, Germany), Edith Sterniczky (Oberwart, Austria), Thomas Stuckert (Zwickau, Germany), Andreas Vécsei (Wien, Austria), Christoph von Buch (Bad Kreuznach, Germany), Tobias Wenzl (Aachen, Germany), Ahlke Willenborg (Berlin, Germany), Ulf Winkler (Bautzen, Germany), Stefan Wirth (Wuppertal, Germany), Harald Andrew Zaunschirm (Krems, Austria), Bernd Zimmer (Rüsselsheim, Germany). 